\title{
René Pommier, René Girard, un allumé qui se prend pour un phare
}

\section{Marianna Marino}

\section{Q OpenEdition}

1 Journals

\section{Edizione digitale}

URL: http://journals.openedition.org/studifrancesi/6106

DOI: 10.4000/studifrancesi.6106

ISSN: 2421-5856

\section{Editore}

Rosenberg \& Sellier

\section{Edizione cartacea}

Data di pubblicazione: 1 mai 2011

Paginazione: 216

ISSN: 0039-2944

\section{Notizia bibliografica digitale}

Marianna Marino, «René Pommier, René Girard, un allumé qui se prend pour un phare», Studi Francesi [Online], 163 (LV | I) | 2011, online dal 30 novembre 2015, consultato il 11 janvier 2021. URL: http:// journals.openedition.org/studifrancesi/6106 ; DOI: https://doi.org/10.4000/studifrancesi.6106

Questo documento è stato generato automaticamente il 11 janvier 2021.

\section{(c) (i) (9)}

Studi Francesi è distribuita con Licenza Creative Commons Attribuzione - Non commerciale - Non opere derivate 4.0 Internazionale. 


\title{
René Pommier, René Girard, un allumé qui se prend pour un phare
}

\author{
Marianna Marino
}

\section{NOTIZIA}

RENÉ POMMIER, René Girard, un allumé qui se prend pour un phare, Paris, Kimé, 2010, pp. 133.

1 Sulla homepage del suo sito (Assez décodé!: http://rene.pommier.free.fr/index.htm), René Pommier si autodefinisce polemista, razionalista, nonché «infatigable pourfendeur de fariboles». Il caustico pamphlet dedicato alla persona e alle opere di René Girard ne è eloquente dimostrazione: esso svela le cantonate secondo lui prese da uno dei più noti pensatori francesi degli ultimi decenni e si prende specialmente gioco della «grande modestie» (p. 7) che lo conduce spesso a farsi carico di una verità incompresa al genere umano fino alla sua venuta.

2 La galleria degli errori presentata da Pommier attraverso la messa in discussione delle letture girardiane (la vicenda di Erode e Salomè come dimostrazione incontrovertibile del desiderio triangolare, per esempio) dà luogo a una sorta di antologia inversa sagace e divertente, ma spesso estenuante. Malgrado tutto, Girard mantiene infatti un'aura quasi eroica (o, meglio, donchisciottesca) grazie al suo orgoglioso snobismo intellettuale.

3 Il volume si articola in capitoletti dai titoli ironici, come Mensonge romantique, vérité romanesque ou élucubrations rocambolesques?, Quand les bras nous en tombent, Quand René Girard nous offre ses salades. Remarques sur la théorie girardienne du sacrifice, René Girard est le messie et Jésus-Christ est son prophète. Ma, sarcasmo a parte, su cosa si basa il metodo confutativo di questo infaticabile e inesorabile razionalista? Le critiche di Pommier ricorrono a strumenti comunissimi e semplicissimi quali la verosimiglianza psicologica e il buonsenso. Si tratta di armi, a dire il vero non troppo affilate, che l'autore contrappone agli eccessi di coloro che della decodifica a oltranza hanno fatto il loro cavallo di battaglia. Girard stesso non è altro che il capro espiatorio della nouvelle 
critique, principalmente rappresentata da Roland Barthes, poiché il primo «vise la même clientèle» (p. 17) del secondo, ovvero i creduloni, i «jobards». Pommier svela i loro segreti di seduzione: la sicumera, l'uso di una retorica totalizzante, l'abilità di svicolare dinanzi alle difficoltà che sorgono dai loro stessi ragionamenti. Dinanzi a tali "immoralità", il razionalista si inalbera e il sarcasmo cede talvolta il passo a una scrittura frettolosa e arrabbiata. Al décodage, Pommier rimprovera in special modo la volontà di storpiare il senso inteso dall'autore. Si ricade però ingenuamente nella trappola dell'intentional fallacy - trappola del resto particolarmente rischiosa dato che i testi cui si fa più spesso riferimento fanno parte di Antico e Nuovo Testamento.

4 Girard non è sicuramente un pensatore ineccepibile e la luce delle sue teorie è forse più flebile di quanto tuonato. Resta il fatto che Pommier, da questo faro inesistente, pare lasciarsi volentieri accecare. 